\section{Diffuse alveolitis as complication of penicillamine treatment for rheumatoid arthritis}

Penicillamine is as effective as gold ${ }^{1}$ when used as an antirheumatic drug. ${ }^{2}$ Side effects may occur, however, the best recognised being marrow suppression, the nephrotic syndrome, abnormalities of taste, rashes, and gastrointestinal disturbances. All are usually reversible on stopping treatment. Nevertheless, deaths have occurred, and recently three fatal cases of Goodpasture's syndrome were reported in patients taking 1 to $3.5 \mathrm{~g}$ penicillamine daily for Wilson's disease over two to three and a half years. ${ }^{3}$ I report a further pulmonary complication of treatment with penicillamine in a patient given small doses for rheumatoid arthritis.

\section{Case report}

A 48-year-old woman had had classic seropositive rheumatoid arthritis for five years. Before starting penicillamine treatment she had received indomethacin continuously and had had two courses of sodium aurothiomalate. The first was stopped after three months because she developed a rash. This did not recur with the second course, which, however, had no therapeutic effect, and two months later she was started on penicillamine $150 \mathrm{mg}$ daily increasing at monthly intervals to $450 \mathrm{mg}$ daily with considerable improvement. Twelve months after starting penicillamine she complained of increasing dyspnoea and a dry cough causing central chest discomfort. She was slightly dyspnoeic at rest, without cyanosis; pulse was 90 beats $/ \mathrm{min}$ and blood pressure $130 / 90 \mathrm{~mm} \mathrm{Hg}$. The heart was not clinically enlarged and the heart sounds were normal. Fine scattered crepitations were heard over both lung bases. The urine contained no red blood cells or albumin and the blood urea was normal. Haemoglobin was $14.9 \mathrm{~g} / \mathrm{dl}$, WBC $8 \times 10^{9} / 1\left(8000 / \mathrm{mm}^{3}\right)$, platelet count $142 \times 10^{9} / 1(142000 /$ $\mathrm{mm}^{3}$ ) and ESR $21 \mathrm{~mm}$ in the first hour (Westergren). The chest $x$-ray picture was of a fibrosing alveolitis (see fig). Three years previously the appearances had been normal. Lung function showed a restrictive pattern with vital capacity 1.951 (predicted normal $2.55 \mathrm{l}$ ), forced expiratory volume in $1 \mathrm{~s}\left(\mathrm{FEV}_{1}\right) 1.51$ (predicted normal 2.21 ), and total lung capacity 2.91 (predicted normal $4.2 \mathrm{l})$. The gas-transfer factor was $3.4 \mathrm{kPa}(26 \mathrm{~mm} \mathrm{Hg})$ (45\% of predicted normal). $\mathrm{PaCO}_{2}(4.8 \mathrm{kPa} ; 36 \mathrm{~mm} \mathrm{Hg})$ and $\mathrm{PaO}_{2}(10.9 \mathrm{kPa}$; $82 \mathrm{~mm} \mathrm{Hg}$ ) were normal.

Penicillamine was stopped and within a week the dyspnoea was improved. A month later it had almost disappeared but the arthritis was again becoming active, and in view of this azathioprine $50 \mathrm{mg}$ daily was started. Chest $x$-ray examination one month later showed considerable improvement with only residual shadowing at the cardiophrenic angles. Three months

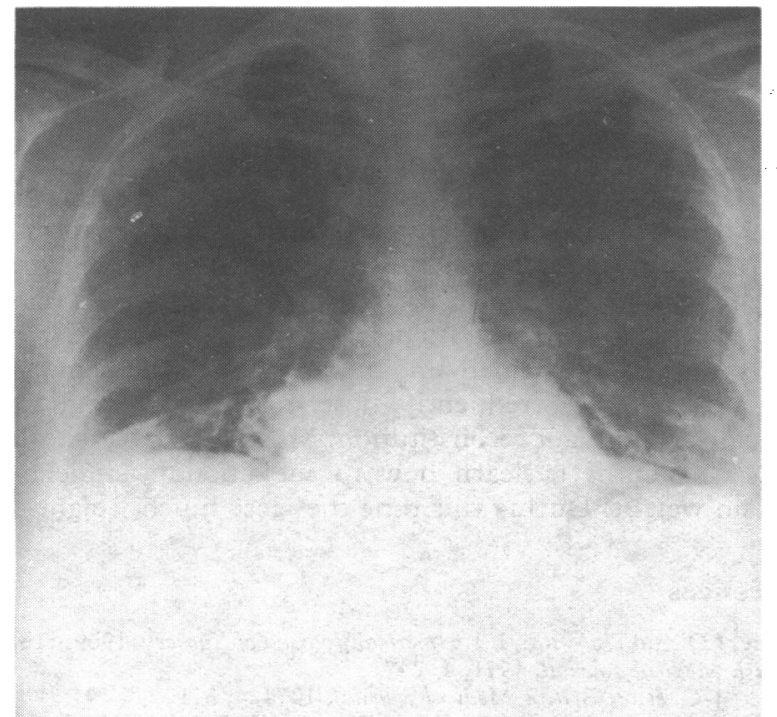

Posteroanterior chest $x$-ray film showing appearances of fibrosing alveolitis. after stopping penicillamine the forced vital capacity $(2.71), \mathrm{FEV}_{1}(2.351)$, and total lung capacity (3.95 1$)$ had returned to normal and the gas-transfer factor had increased to $4.8 \mathrm{kPa}(36 \mathrm{~mm} \mathrm{Hg})(65 \%$ of predicted normal), the blood gases remaining within normal limits.

\section{Comment}

Though histological proof of diffuse alveolitis was not available in this case, the radiological features and abnormalities in pulmonary function were strongly suggestive. Other causes of the diffuse alveolitis cannot be completely excluded but the fact that it developed while the patient was on penicillamine and improved immediately on stopping this drug strongly suggests that it was induced by penicillamine. The ultimate test would be a repeat challenge with penicillamine, but this might be at the risk of producing an irreversible lesion.

${ }^{1}$ Huskisson, E C, et al, Annals of the Rheumatic Diseases, 1974, 33, 532.

2 Multicentre Trial Group, Lancet, 1973, 1, 275.

3 Sternlieb, I, Bennett, B, and Scheinberg, I H, Annals of Internal Medicine, $1975,82,673$.

Department of Medicine, University of Liverpool, Liverpool L69 3BX

C J EASTMOND, MRCP, research fellow

\section{Prospective randomised trial of early postoperative bathing}

The validity of allowing patients to bath in the early postoperative period was tested in a pilot scheme when 20 patients were allowed either a full-immersion bath or a shower from the third day after operation. Encouraged by an enthusiastic response from patients we organised a randomised prospective trial. This was designed to assess the risks of sepsis and delayed healing and discharge from hospital in patients allowed to take baths soon after operation compared with those in patients given traditional wound care. Beneficial effects from early postoperative bathing have been noted. ${ }^{1}$

\section{Patients, methods, and results}

One hundred inpatients normally able to bath took part in the trial. The presence of Redivac, tube, or corrugated drains did not preclude bathing. Patients were allocated preoperatively by random card selection to a "traditional" or "bather" group. All had the original wound dressing removed on the second day after operation and the wound sprayed with a clear plastic dressing (Hibispray 4). Patients in the bather group were then allowed either a daily shower or full-immersion bath. The enamel baths used were prepared so as to reduce flora and prevent cross-infection. They were cleaned before and after with hot water and abrasive hypochlorite powder to reduce the bacteria count, as advocated by Boycott. ${ }^{2}$ To each bath of hot water (115-135 1) $30 \mathrm{ml}$ hexachlorophane bath concentrate was added to eliminate staphylococci and reduce other surface bacteria. ${ }^{34}$ The clear plastic dressing used was made up of a resin in ethyl acetate, which is deposited as a film on evaporation of a volatile solvent and contains chlorhexidine. Wounds were classed as infected if there was: (a) confluent erythema or cellulitis around the wound, with or without bacteriological confirmation; $(b)$ discharge of pus from the wound or sutures; or $(c)$ release of deep-seated infected haematoma despite good initial skin healing.

The 100 patients had 108 surgical wounds, which were found to be equally distributed between the two groups. In each group four wounds were infected (see table). There was no appreciable difference between the groups in the timing of removal of sutures, 83 patients having them removed by the eighth postoperative day. Primary skin healing took place in all the infected 